\title{
The influence of temperature and food supply on the development of Adalia bipunctata (Coleoptera: Coccinellidae)
}

\author{
INGO SCHÜDER ${ }^{1 *}$, MARTIN HOMMES ${ }^{2}$ and OTTO LARINK ${ }^{1}$ \\ ${ }^{1}$ University of Braunschweig, Spielmannstraße 7, 38.106 Braunschweig, Germany; e-mail: O.Larink@tu-bs.de \\ ${ }^{2}$ Federal Biological Research Centre (BBA), Messeweg 10-12, 38.104 Braunschweig, Germany; e-mail: M.Hommes@bba.de
}

Keywords. Adalia bipunctata, Sitobion avenae, Coccinellidae, Aphidae, biological control, greenhouse

\begin{abstract}
The development of Adalia bipunctata larvae feeding on the grain aphid Sitobion avenae was investigated at 15, 20 and $25^{\circ} \mathrm{C}$ and two different levels of food supply. Increased temperatures accelerated development and reduced mortality rates. A reduced food supply slowed down development and increased mortality at all life stages. The total food intake of larvae ranged from 24-65 mg, which is equivalent to up to 190 aphids. Larvae compensated for low food supply by reducing development rates, high prey exploitation efficiencies, reaching up to $100 \%$, and by high prey-biomass conversion efficiencies, reaching over $40 \%$. The findings are discussed under the aspect of suitability of A. bipunctata as a biological control agent for greenhouse-specific aphid pest species.
\end{abstract}

\section{INTRODUCTION}

Ladybirds have been used as biological control agents since the early 20th century (Hodek, 1970). The coccidophagous species such as Rodolia cardinalis (Mulsant) have been used very successfully. However, the control of aphids with ladybirds remains very difficult, because of the fast development of the aphids and their high rate of reproduction, as well as problems with the space and manpower required for mass rearing of coccinellids.

There are various factors that influence the success of a coccinellid aphid predator. Early work with Adalia bipunctata L. showed that the ability of larvae to survive depends on their success in finding suitable prey early enough (Banks, 1957). Other investigations led to the understanding that plant structure, plant volatiles and aphid prey quality play an important role in the foraging behaviour and predatory success (Carter et al., 1984; Grevstad \& Klepetka, 1992; Ferran \& Dixon, 1993; Kalushkov, 1999; Ninkovic et al., 2001). Kalushkov (1994, 1998) systematically investigated the effect of different aphid species on the development of $A$. bipunctata larvae. He suggested a link between the palatability of the aphid species and the secondary plant metabolites they accumulated by feeding on their host plants.

The grain aphid Sitobion avenae was known to be a prey species for $A$. bipunctata, as this prey can supply the predator with all essential nutrients. This makes this aphid a promising candidate for effective breeding of $A$. bipunctata in cultures. From work with Coccinella septempunctata L. it is known that prey availability in non-crop habitats can have an important influence on predator impact in the crop (Bianchi \& van der Werf, in press). Previous experiments in greenhouses of the Federal Biological Research Centre for Agriculture and Forestry (unpublished data) suggested using an open culture of such a highly palatable and host-specialised aphid species. This could maintain a permanent food source for aphidophagous coccinellids in the greenhouse and would help to establish a ladybird population with the aim to control other aphid species such as Myzus persicae (Sulzer), Aphis gossypii Glover or Macrosiphum solani (Kittel).

The aims of the research presented in this paper were to:

1) Identify the impact of temperature and quantity of food supply on the duration of development, mortality rate and final body weight of $A$. bipunctata larvae and pupae.

2) Investigate if there are mechanisms, by which a strong reduction in food supply could be compensated by the ladybirds.

3) Assess the potential of $A$. bipunctata for the biological control of aphids, e.g. their tolerance of physical stress, and to develop suggestions for optimising their practical use in greenhouses.

\section{MATERIAL AND METHODS}

Eggs of A. bipunctata were kept under controlled laboratory conditions at a constant temperature of $15^{\circ} \mathrm{C}, 20^{\circ} \mathrm{C}$ and $25^{\circ} \mathrm{C}$ and a photoperiod of $16 \mathrm{~L}: 8 \mathrm{D}$. Every morning, larvae hatch was recorded. On the day following the observation of hatch larvae were removed from the egg batch and then kept separately in 55 $\mathrm{mm}$ plastic Petri dishes lined with a filter paper and a piece of moist cotton wool. There were six different treatments (Table 1). Larvae were fed three times a week with a defined fresh weight (Table 2) of Sitobion avenae, which had been established on a $1 \times 4 \mathrm{~cm}$ piece of wheat leaf after weighing. The amount of food given per feeding interval corresponded to the sum of daily food amounts as given in Table 2. At 20 and $25^{\circ} \mathrm{C}$ ladybird larvae were fed with aphid instars I and II only for the first two

* Corresponding and present address: University of Newcastle upon Tyne, School of Biology, Ridley Building, Newcastle-uponTyne, NE1 7RU, UK; e-mail: Ingo.Schuder@defra.gsi.gov.uk 
TABLE 1. Treatment combinations used to investigate the development of Adalia bipunctata larvae (with completed development). "Reduced" food supply was $25 \%$ of what larvae fed when aphids were offered in excess.

\begin{tabular}{ccccc}
\hline Treatment & $\begin{array}{c}\text { Larvae } \\
\text { (start) }[\mathrm{n}]\end{array}$ & $\begin{array}{c}\text { Larvae } \\
\text { (pupated) }[\mathrm{n}]\end{array}$ & $\begin{array}{c}\text { Temperature } \\
{\left[{ }^{\circ} \mathrm{C}\right]}\end{array}$ & $\begin{array}{c}\text { Food } \\
\text { supply }\end{array}$ \\
\hline $15 \mathrm{r}$ & 118 & 42 & $15^{\circ} \mathrm{C}$ & reduced \\
$15 \mathrm{e}$ & 65 & 33 & $15^{\circ} \mathrm{C}$ & excess \\
$20 \mathrm{r}$ & 98 & 37 & $20^{\circ} \mathrm{C}$ & reduced \\
$20 \mathrm{e}$ & 61 & 32 & $20^{\circ} \mathrm{C}$ & excess \\
$25 \mathrm{r}$ & 92 & 40 & $25^{\circ} \mathrm{C}$ & reduced \\
$25 \mathrm{e}$ & 57 & 37 & $25^{\circ} \mathrm{C}$ & excess \\
\hline
\end{tabular}

days, with aphid instars I-IV only for the following two days and with instars and adult aphids thereafter. At $15^{\circ} \mathrm{C}$ ladybird larvae were fed with aphid instars I and II only for the first four days, with aphid instars I-IV only for the following four days and with instars and adult aphids thereafter.

The aphids not eaten until the next feeding event were removed and their fresh weight recorded in order to determine the larval food intake. Preliminary trials showed that the reduction in fresh weight due to desiccation was marginal, as it was compensated for by reproduction and growth of aphids established on a wheat leaf. It was impossible and unpractical to feed all larvae at exactly the same intervals, as they hatched on different days of the week. Consequently, daily food intake was calculated as the average food intake over a given period of time (two or three day feeding interval).

The food conversion rate (\%) of the ladybirds was defined as follows:

$$
\frac{\text { maximum fresh weight of ladybird larvae }(\mathrm{mg})}{\text { fresh weight of aphids consumed }(\mathrm{mg})} \times 100
$$

The food exploitation efficiency (\%), when food was scarce, was defined as follows:

$$
\frac{\text { fresh weight of aphids consumed }(\mathrm{mg})}{\text { fresh weight of aphids offered }(\mathrm{mg})} \times 100
$$

The larval development stage was assessed every day. The temperature threshold for egg and pupal development were extrapolated. It was assumed that a certain total energy input (measured in day degrees above the temperature threshold) is necessary for a physiological process. The threshold was determined by a process of multiple iteration. That temperature was defined as the threshold for the physiological process, at which the required day degrees (product of actually observed duration of the process times respective temperature above threshold) were closest together (measured as the smallest possible standard deviation of the mean of values of the three temperatures).

Only those larvae, which completed their development and pupated, were included in the analysis for food consumption and conversion rates and development times. Continuous data was tested for normal distribution. If normal distribution was given, data were analysed with an analysis of variance (ANOVA) and a Tukey post hoc procedure, if not, they were analysed with a non-parametric equivalent, the Kruskal-Wallis test and a post hoc procedure according to Zar (1999). Binomial data were analysed with a g-test and a post hoc procedure according to Wilcoxon \& Wilcox (1964) as cited in (1999). Some data on growth development and food intake were analysed with a regression model.
TABLE 2. Fresh weight of grain aphids (Sitobion avenae) fed to Adalia bipunctata larvae in the six different treatments. Abbreviation of treatments as in Table 1.

\begin{tabular}{rrrrrrr}
\hline \multirow{2}{*}{$\begin{array}{c}\text { Day after } \\
\text { hatch }\end{array}$} & \multicolumn{6}{c}{ Treatments } \\
\cline { 2 - 6 } & $15 \mathrm{e}$ & $20 \mathrm{e}$ & $25 \mathrm{e}$ & $15 \mathrm{r}$ & $20 \mathrm{r}$ & $25 \mathrm{r}$ \\
\cline { 2 - 6 } & \multicolumn{5}{c}{ Aphids fed - fresh weight } & {$[\mathrm{mg}]$} \\
\hline 3 & 2.0 & 2.5 & 2.5 & 2.0 & 2.0 & 2.0 \\
4 & 2.0 & 2.5 & 2.5 & 2.0 & 2.0 & 2.0 \\
5 & 2.0 & 5.0 & 7.5 & 2.0 & 0.4 & 0.9 \\
6 & 3.0 & 8.0 & 7.5 & 2.0 & 1.0 & 0.9 \\
7 & 3.0 & 8.0 & 16.0 & 1.5 & 1.0 & 3.0 \\
8 & 5.0 & 8.0 & 25.0 & 1.5 & 1.0 & 4.0 \\
9 & 5.0 & 16.0 & 25.0 & 0.4 & 2.0 & 4.0 \\
10 & 7.5 & 20.0 & 25.0 & 0.4 & 3.5 & 5.0 \\
11 & 7.5 & 20.0 & & 0.7 & 3.5 & 5.0 \\
12 & 10 & 20.0 & & 0.7 & 3.3 & 5.0 \\
13 & 10 & 20.0 & & 1.5 & 3.3 & \\
14 & 10 & 20.0 & & 1.5 & 3.3 & \\
15 & 12.5 & 20.0 & & 1.6 & 3.3 & \\
16 & 12.5 & 20.0 & & 1.6 & 3.3 & \\
17 & 20 & & & 2.3 & 3.3 & \\
$>17$ & 20 & & & 2.8 & 3.3 & \\
\hline
\end{tabular}

\section{RESULTS}

\section{Development of $\boldsymbol{A}$. bipunctata}

A total of 221 of the initial 491 larvae completed their development and pupated. The data for these are presented below.

The mean duration of development from the egg to the emergence of the imago was affected by both temperature and the amount of food offered (Table 3 ). The development was slowest at $15^{\circ} \mathrm{C}$ and reduced food supply (44 days) and fastest at $25^{\circ} \mathrm{C}$ and food in excess (16 days). A reduction of food supply at the same temperature extended the total development time by up to four days, but this was not significant (Kruskal-Wallis test: $\mathrm{N}=185$, df $=5, \mathrm{Chi}^{2}=177.3, P>0.05$, Table 3$)$. An increase of temperature by $5^{\circ} \mathrm{C}$ at the same level of food given ("excess" or "reduced") significantly decreased the development time by up to 16 days (Kruskal-Wallis test: $\mathrm{N}=$ $185, \mathrm{Chi}^{2}=177.3, \mathrm{df}=5, P<0.001$, Table 3 ).

Temperature influenced the duration of the separate development stages, with significant differences caused in the duration of first larval instar and pupae stages between all temperatures regardless of the level of food (previously) given (Kruskal-Wallis-test, details in Table 3 ). For other larval instars temperature only had a significant effect when comparing the same level of food given. For example, 2nd instar larvae fed in excess developed significantly faster at $25^{\circ} \mathrm{C}$ than at $20^{\circ} \mathrm{C}$ (Kruskal-Wallis test: $\mathrm{N}=221$, df $=5, \mathrm{Chi}^{2}=125.1, P<0.001$, Table 3 ).

The amount of food given had a significant influence on larval development at the same temperature in two cases: the 3rd larval instar at 20 and $25^{\circ} \mathrm{C}$ (KruskalWallis test: $\mathrm{N}=221$, df $=5, \mathrm{Chi}^{2}=123.5, P<0.001$, Table 3). The variation of development time at $15^{\circ} \mathrm{C}$ was 
TABLE 3. Development time (mean $\pm \mathrm{SE}$ ) of life stages of Adalia bipunctata. Different letters in the same column indicate significant differences in the development time $(\mathrm{P}<0.001)$. Abbreviations of treatments as in Table 1.

\begin{tabular}{cccccccccc}
\hline \multirow{2}{*}{ Treatment } & \multirow{2}{*}{ Larvae [n] } & \multirow{2}{*}{ Imago [n] } & \multicolumn{7}{c}{ Development of stage [d] } \\
\cline { 4 - 10 } & & & Egg & L1 & L2 & L3 & L4 & Pupae & Total \\
\hline $15 \mathrm{r}$ & 42 & 32 & $7.1 \pm 0.0 \mathrm{a}$ & $6.4 \pm 0.2 \mathrm{a}$ & $4.4 \pm 0.3 \mathrm{a}$ & $4.9 \pm 0.3 \mathrm{a}$ & $7.8 \pm 0.3 \mathrm{a}$ & $13.8 \pm 0.1 \mathrm{a}$ & $44.4 \pm 0.3 \mathrm{a}$ \\
$15 \mathrm{e}$ & 33 & 31 & $6.4 \pm 0.1 \mathrm{a}$ & $5.9 \pm 0.3 \mathrm{a}$ & $3.8 \pm 0.3 \mathrm{ab}$ & $3.7 \pm 0.3 \mathrm{ab}$ & $7.5 \pm 0.4 \mathrm{a}$ & $13.7 \pm 0.2 \mathrm{a}$ & $41.0 \pm 0.3 \mathrm{ab}$ \\
$20 \mathrm{r}$ & 37 & 31 & $4.3 \pm 0.1 \mathrm{~b}$ & $3.5 \pm 0.2 \mathrm{~b}$ & $3.5 \pm 0.2 \mathrm{ab}$ & $2.7 \pm 0.1 \mathrm{~b}$ & $5.9 \pm 0.2 \mathrm{a}$ & $9.2 \pm 0.1 \mathrm{~b}$ & $29.2 \pm 0.2 \mathrm{bc}$ \\
$20 \mathrm{e}$ & 32 & 29 & $4.1 \pm 0.1 \mathrm{~b}$ & $4.0 \pm 0.1 \mathrm{~b}$ & $2.9 \pm 0.1 \mathrm{~b}$ & $2.0 \pm 0.1 \mathrm{c}$ & $3.6 \pm 0.2 \mathrm{~b}$ & $8.5 \pm 0.1 \mathrm{~b}$ & $24.9 \pm 0.2 \mathrm{~cd}$ \\
$25 \mathrm{r}$ & 40 & 29 & $3.0 \pm 0.0 \mathrm{c}$ & $2.8 \pm 0.3 \mathrm{c}$ & $2.1 \pm 0.0 \mathrm{c}$ & $2.8 \pm 0.1 \mathrm{~b}$ & $2.5 \pm 0.1 \mathrm{bc}$ & $5.3 \pm 0.1 \mathrm{c}$ & $18.4 \pm 0.3 \mathrm{de}$ \\
$25 \mathrm{e}$ & 37 & 33 & $3.0 \pm 0.0 \mathrm{c}$ & $2.0 \pm 0.0 \mathrm{c}$ & $1.9 \pm 0.1 \mathrm{c}$ & $1.8 \pm 0.1 \mathrm{c}$ & $1.9 \pm 0.1 \mathrm{c}$ & $5.1 \pm 0.1 \mathrm{c}$ & $15.6 \pm 0.1 \mathrm{e}$ \\
$P$ & & & $<0.001$ & $<0.001$ & $<0.001$ & $<0.001$ & $<0.001$ & $<0.001$ & $<0.001$ \\
\hline
\end{tabular}

so great that no significant differences between larvae fed in excess and at reduced food supply could be found.

The temperature threshold for egg development was extrapolated as $7.2^{\circ} \mathrm{C}$ (53 day degrees above threshold necessary until hatch), that for pupal development (based on pupae from larvae fed in excess) as $8.9^{\circ} \mathrm{C}$ (87 day degrees).

\section{Feeding and growing of $\boldsymbol{A}$. bipunctata larvae}

The mean total food intake ranged between $24 \mathrm{mg}$ and $60 \mathrm{mg}$ per larva (Table 4) The maximum value amounted to 150 to 190 aphids and was achieved in larvae kept at $15^{\circ}$, where it was significantly higher than in all other treatments (ANOVA: $\mathrm{N}=221$, $\mathrm{df}=5, \mathrm{~F}=185.3, P<$ 0.001 , Table 4).

When fed in excess the calculated daily food intake of the larvae increased logistically with larval age (regression model: $15^{\circ} \mathrm{C}: \mathrm{n}=33, \mathrm{df}=25, \mathrm{~F}=220.0, \mathrm{R} 2=0.898$, $P<0.001 ; 20^{\circ} \mathrm{C}: \mathrm{n}=32, \mathrm{df}=13, \mathrm{~F}=105.3, \mathrm{R} 2=0.890$, $P<0.001 ; 25^{\circ} \mathrm{C}: \mathrm{n}=37, \mathrm{df}=7, \mathrm{~F}=81.8, \mathrm{R} 2=0.921, P$ $<0.001$; Fig. 1). Towards the end of the development, shortly before pupation, the maximum calculated daily food intake was $20 \mathrm{mg}, 13 \mathrm{mg}$ and $10 \mathrm{mg}$ at $25^{\circ} \mathrm{C}, 20^{\circ} \mathrm{C}$ and $15^{\circ} \mathrm{C}$, respectively.

When given a reduced food supply, the larvae had a very high efficiency of exploiting the scarce food source. Exploitation efficiency was defined as the proportion of offered food eaten before the next feeding event. In all three treatments some individuals ate nearly $100 \%$ of all the aphids supplied during their whole development.

TABLE 4. Total food intake (fresh weight) and food conversion rate (mean $\pm \mathrm{SE}$ ) of Adalia bipunctata larvae. Different letters in the same column indicate significant differences in the development time $(\mathrm{P}<0.001)$. Abbreviations of treatments as in Table 1 .

\begin{tabular}{ccccc}
\hline Treatment & {$[\mathrm{n}]$} & $\begin{array}{c}\text { Total food intake } \\
{[\mathrm{mg}]}\end{array}$ & {$[\mathrm{n}]$} & $\begin{array}{c}\text { Food conversion rate } \\
{[\%]}\end{array}$ \\
\hline $15 \mathrm{r}$ & 42 & $25.4 \pm 0.5 \mathrm{~cd}$ & 31 & $40.3 \pm 0.9 \mathrm{a}$ \\
$15 \mathrm{e}$ & 33 & $64.7 \pm 1.7 \mathrm{a}$ & 33 & $22.0 \pm 0.8 \mathrm{e}$ \\
$20 \mathrm{r}$ & 37 & $28.1 \pm 0.9 \mathrm{c}$ & 32 & $34.2 \pm 1.5 \mathrm{bc}$ \\
$20 \mathrm{e}$ & 32 & $56.9 \pm 1.1 \mathrm{~b}$ & 31 & $28.1 \pm 0.7 \mathrm{~d}$ \\
$25 \mathrm{r}$ & 40 & $24.1 \pm 0.6 \mathrm{~d}$ & 34 & $37.5 \pm 1.2 \mathrm{ab}$ \\
$25 \mathrm{e}$ & 37 & $51.5 \pm 1.6 \mathrm{~b}$ & 35 & $29.4 \pm 1.6 \mathrm{~cd}$ \\
$P$ & & $<0.001$ & & $<0.001$ \\
\hline
\end{tabular}

However, there was also evidence that the larvae had difficulty in exploiting the complete food supply at $15^{\circ} \mathrm{C}$. With an overall exploitation rate of $75 \%$ at $15^{\circ} \mathrm{C}$ and it was significantly lower than at $20^{\circ} \mathrm{C}$ or $25^{\circ} \mathrm{C}$ (ANOVA: $\mathrm{N}=119$, df $=2, \mathrm{~F}=8.5, P<0.001$, Fig. 2). At all temperatures the exploitation rate grew with larval age. At 15 and $20^{\circ} \mathrm{C}$ this growth was logarithmical (Regression analysis: $15^{\circ} \mathrm{C}: \mathrm{n}=42, \mathrm{df}=11, \mathrm{~F}=112.9, \mathrm{R}^{2}=0.911, P$ $<0.001 ; 20^{\circ} \mathrm{C}: \mathrm{n}=37, \mathrm{df}=4, \mathrm{~F}=22.2, \mathrm{R}^{2}=0.848, P<$ 0.01 , Fig. 2). The development at $25^{\circ} \mathrm{C}$ was too fast to provide enough data for such an analysis.

Larvae which were fed reduced food amounts showed higher conversion efficiency (mg body mass increase per mg aphid eaten) than those fed in excess (ANOVA: $\mathrm{N}=$ 196 , df $=5, \mathrm{~F}=38.4, P<0.001$, Table 4$)$. The reduced food supply treatments had values as high as $40 \%$, i.e. built $0.4 \mathrm{mg}$ biomass per $\mathrm{mg}$ aphid food eaten. The larvae fed in excess had food conversions efficiencies of 20-29\%.

Eating a high number of aphids with a high efficiency led to a very fast increase in weight (gain) within a relatively short period of time (Fig. 3). Starting with $0.2 \mathrm{mg}$ fresh weight at the end of the first larval stage individual larvae reached up to $19 \mathrm{mg}$ at the end of the larval stage. The pupal weights of the larvae fed in excess, with values of 13-16 mg, were higher than those of respective variables with reduced food supply (9-10 mg). During the larval development the mean growth rates were $0.6,1.0$ and $1.9 \mathrm{mg}$ /day for 15,20 and $25^{\circ} \mathrm{C}$ respectively.

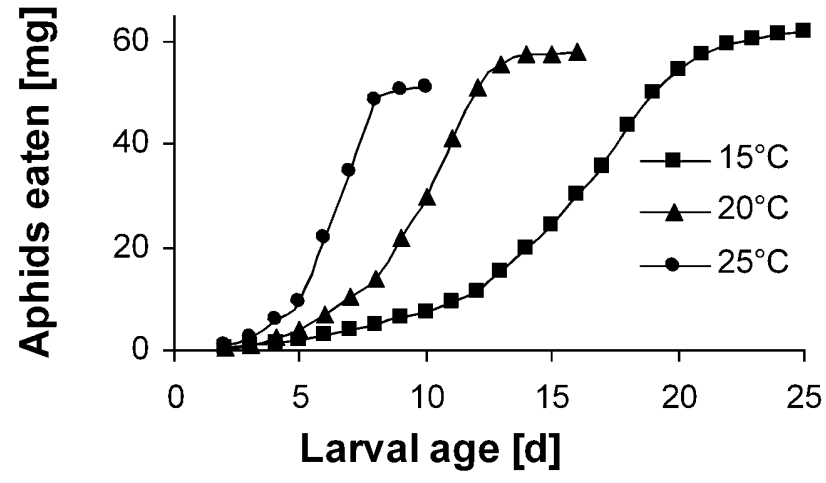

Fig 1. Accumulated food uptake by Adalia bipunctata larvae when fed in excess (fresh weight of Sitobion avenae). Lines end when pupation sets in. 


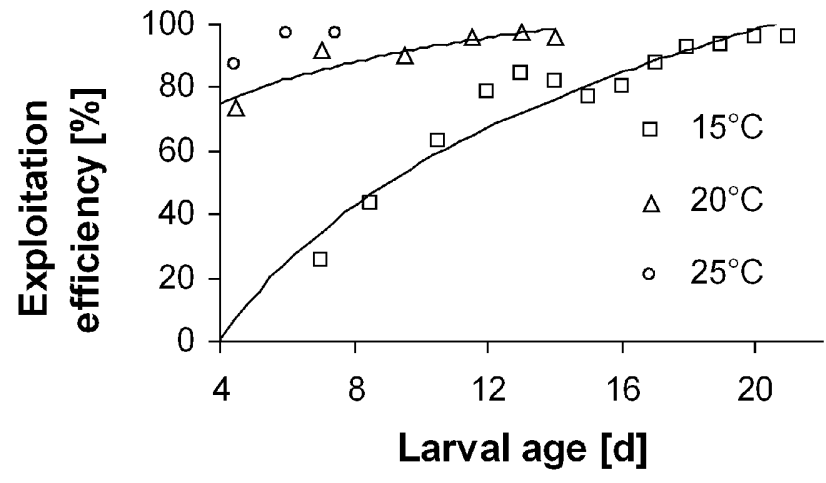

Fig. 2. Exploitation efficiency of Adalia bipunctata larvae at different temperatures and with reduced food supply in relation to larval age. Lines for $15^{\circ} \mathrm{C}$ and $20^{\circ} \mathrm{C}$ represent logarithmic best fit trend line.

\section{Life-stage specific mortality rates of $\boldsymbol{A}$. bipunctata}

When compared within each larval instar, the treatment (temperature and food supply) did not have significant effects on mortality of specific larval stages except the second instar (G-test for second instar: $\mathrm{N}=191, \mathrm{df}=5, \mathrm{G}$ $=11.7, P<0.05$, Table 5). However, the mortality rate over the whole larval stage in the different treatments did differ significantly (G-Test: $\mathrm{N}=491, \mathrm{df}=5, \mathrm{G}=17.5, P$ $<0.01$, Table 5). It was highest, with a value of $62 \%$, at $15^{\circ} \mathrm{C}$ with reduced food supply and was lowest, with a value of $33 \%$, at $25^{\circ} \mathrm{C}$ with food in excess. In all treatments mortality was highest during the first larval stage (28-46\%) followed by the pupal stage $(6-30 \%)$. The stages in between had much lower mortality rates.

There was a trend of high temperatures reducing the mortality rate in general. Comparing the effects of feeding regime without regard to the temperature showed that supplying insufficient food raised the mortality rates by 6 to $30 \%$. For some stages such as the first larval stage or the pupal stage, where mortality was already high when aphids were fed in excess the mortality was increased even more (Table 5).

\section{DISCUSSION AND CONCLUSIONS}

\section{Development of $\boldsymbol{A}$. bipunctata larvae}

The observations show that $S$. avenae could be a good food source for breeding $A$. bipunctata. For example, the larval development of $A$. bipunctata took 17 days when

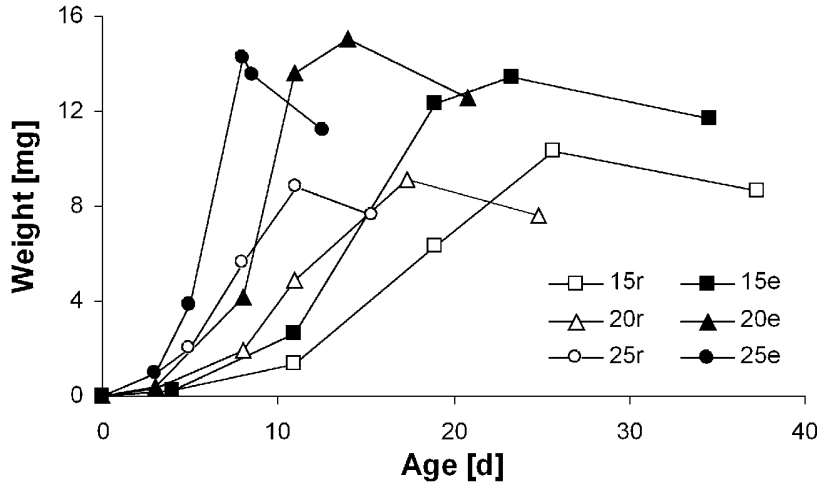

Fig. 3. Fresh body weight of Adalia bipunctata: egg (1st datapoint), larvae (2nd-4th datapoint), pupae (5th datapoint) and newly emerged adults (last datapoint) after feeding. Abbreviations of treatments as in Table 1.

fed with M. persicae at $20^{\circ} \mathrm{C}$ (Hämäläinen et al., 1975), which is four days longer than in the present study. Similarly at $14^{\circ} \mathrm{C}$, development with Eucallipterus tiliae L. as food source resulted in a development duration of 30 days (Wratten, 1973), whereas with $S$. avenae in our results it was only 21 days at $15^{\circ} \mathrm{C}$.

The results suggest that a reduction in temperature has a stronger impact on development times of larvae than a reduction in food supply. At the same temperature a strong reduction in food supply prolonged the total duration of larval development by $8-15 \%$ (3-4 days). Even though significant differences for the duration of individual instars were generally not obtained, there was an overwhelmingly clear pattern that larvae feeding in excess developed on average faster than those with a reduced food supply (Table 3 ).

However, comparing the same feeding regimes (food in excess or reduced food supply), reducing the temperature by $5^{\circ} \mathrm{C}$ prolonged the development by $34-39 \%(9-15$ days, Table 3). The observation of Wratten (1973) of doubling or even tripling duration times with reduced food supply could not be confirmed.

The extrapolation of thresholds for egg and pupal development should be regarded as a guideline only, as it is only based on three temperature regimes and other general assumptions such as non-linear response to temperature (Bonhomme, 2000) could not be taken into account. However, they give a good indication that $A$. bipunctata

TABLE 5. Mortality rates (\% dying in each life stage) of Adalia bipunctata at different life stages $(\mathrm{L}=$ larval instar). Different letters in the same column indicate significant differences in the mortality rate. Treatment abbreviations as in Table 1.

\begin{tabular}{ccccccccccc}
\hline \multirow{2}{*}{ Treatment } & $\begin{array}{c}\text { Larvae } \\
\text { (hatch) [n] }\end{array}$ & Pupae [n] & Imago [n] & \multicolumn{7}{c}{ Mortality rate at life stage } \\
\cline { 5 - 11 } & & & L1 & L2 & L3 & L4 & Larvae & Pupae & Total \\
\hline $15 \mathrm{r}$ & 118 & 42 & 32 & 46 & $9 \mathrm{a}$ & 12 & 12 & $62 \mathrm{a}$ & $29 \mathrm{a}$ & $73 \mathrm{a}$ \\
$15 \mathrm{e}$ & 65 & 33 & 31 & 42 & $5 \mathrm{ab}$ & 3 & 6 & $49 \mathrm{ab}$ & $6 \mathrm{~b}$ & $52 \mathrm{ab}$ \\
$20 \mathrm{r}$ & 98 & 37 & 31 & 38 & $15 \mathrm{a}$ & 4 & 16 & $57 \mathrm{a}$ & $26 \mathrm{~b}$ & $68 \mathrm{a}$ \\
$20 \mathrm{e}$ & 61 & 32 & 29 & 28 & $14 \mathrm{a}$ & 3 & 8 & $44 \mathrm{ab}$ & $15 \mathrm{ab}$ & $52 \mathrm{ab}$ \\
$25 \mathrm{r}$ & 92 & 40 & 29 & 43 & $8 \mathrm{ab}$ & 6 & 9 & $55 \mathrm{a}$ & $29 \mathrm{a}$ & $68 \mathrm{ab}$ \\
$25 \mathrm{e}$ & 57 & 37 & 33 & 28 & $0 \mathrm{~b}$ & 0 & 5 & $32 \mathrm{~b}$ & $15 \mathrm{ab}$ & $42 \mathrm{~b}$ \\
$P$ & & & & 0.089 & $<0.05$ & 0.077 & 0.499 & $<0.01$ & $<0.05$ & $<0.001$ \\
\hline
\end{tabular}


could have a slow but steady development even at low greenhouse temperatures during colder seasons. The calculated temperature threshold for egg development of $7.2^{\circ} \mathrm{C}$, with 53 day degrees (DD) required, is below that found by Frazer \& McGregor (1992, $8.4^{\circ} \mathrm{C}, 48$ DD). Apparently, A. bipunctata has a lower egg development threshold than other Coccinellidae (Frazer \& McGregor, 1992; Xia et al., 1999). More research at lower temperatures would be necessary to confirm the observed trends and proposed thresholds.

The total food intake of $A$. bipunctata larvae at $20^{\circ} \mathrm{C}$ (57 mg) was comparable to values found for the same species when fed on Aphis fabae Scopoli (58 mg), but lower than that recorded for M. persicae (69 mg, Blackman, 1967). At $15^{\circ} \mathrm{C}$ the total food intake was probably higher than at 20 or $25^{\circ} \mathrm{C}$, because of the much longer duration of the development and a higher cost for the metabolism. Hämäläinen et al. (1975) expressed the amount of $M$. persicae eaten in the number of aphids ( 863 at $20^{\circ} \mathrm{C}$ ). Similar data is given for the consumption of $A$. fabae at $15^{\circ} \mathrm{C}(240$ aphids, Olszak, 1987). However, the number of prey seems a rather imprecise measure, especially when comparing aphids of different size.

Depending on temperature and age, the larval exploitation efficiency at low prey densities ("reduced" food supply) rose to nearly $100 \%$. This means that - at least on a small scale - larvae find nearly all aphids and the risk of starvation stays low even at low prey densities. The very high exploitation efficiencies observed in our own studies were much higher than those found by Blackman (1967) for fourth instar A. bipunctata larvae feeding on M. persicae $(40 \%)$ or $A$. fabae (24\%). Exploitation efficiencies at $20^{\circ} \mathrm{C}(74 \%)$ were more in line with results from first instar $A$. bipunctata feeding on Drepanosiphum platanoides (Schrank) at $21^{\circ} \mathrm{C}(85-93 \%$, Dixon, 1970).

The larvae displayed several mechanisms to compensate for a lack of food. One of them was to slow down the development. Once there is food in excess again they are able to respond to a high food supply. The other was an increase in the conversion efficiency. The established food conversion rates into biomass (34-40\% when fed with reduced food supply, Table 4) were between the values found for $A$. bipunctata fourth instar larvae fed on M. persicae (45\%) or A. fabae (28\%, Blackman, 1967). From the second larval stage onwards there could potentially be an exponential rise in food consumption.

There were remarkable differences in larval mortality (32-62\%) depending on temperature and food supply (Table 5). There were clear trends of increasing mortality with decreasing temperature and reduced food supply. The latter effect appeared to be stronger, highlighting the need of a permanently available food source to help the establishment and growth of a population. When using other aphid species such as $A$. pomi as the food source the mortality rate can be as high as $93 \%$, but with other species, such as $A$. fabae, also slightly lower (27\%) (Olszak, 1987).

The larval growth rates were between 0.6 and 1.9 $\mathrm{mg}$ /day in comparison to $0.4-0.9 \mathrm{mg}$ /day when fed with
Aphis pomi DeGeer or Rhopalosiphum insertum (Walker) (Olszak, 1987). Maximum larval weight found for diets with aphid species such as Microlophium carnosum (Buckton), M. persicae, and A. fabae were between 12 and $16 \mathrm{mg}$ at $20^{\circ} \mathrm{C}$ (Blackman, 1967), which compares to $15.1 \mathrm{mg}$ mean larvae weight found when fed with $S$. avenae at $20^{\circ} \mathrm{C}$.

\section{Implications for the use of $A$. bipunctata as biological control agent}

The active larval period between egg hatch and pupation is the time period when larvae are available for biological control. This period was between six and 17 days long. To avoid an interruption in the feeding activity while pupation is taking place, new larvae would have to be introduced at appropriate intervals.

Under the optimal conditions used here $\left(20^{\circ} \mathrm{C}\right.$ and 16 hours light), 12 generations were bred in the laboratory, exclusively on $S$. avenae without any obvious detrimental effect on the viability of $A$. bipunctata. High temperatures, artificial light sources and a satisfactory food supply in the greenhouse (introduced $S$. avenae colonies) could break the natural univoltine cycle and bring forth several generations, which would multiply the total food intake of the ladybirds.

It can be concluded that $S$. avenae could be used in two ways:

(1) Breeding of $A$. bipunctata larvae in the laboratory for later release of larvae or adults in the greenhouse.

The data suggest that first instar larvae should not be used as natural enemies:

(a) The mortality of first instar larvae is very high, even when food is supplied in excess (Table 5).

(b) Young larvae tend to cannibalise, especially if aphid prey is scarce (Merritt Hawkes, 1920; Hodek, 1970; Agarwala, 1991; Agarwala \& Dixon, 1992; Yasuda \& Ohnuma, 1999). In our own studies cannibalism was avoided by growing larvae separately as soon as they became active (day2).

(c) Young larvae have a relatively high activity rate. However, their mobility is strongly limited, they are not very efficient and they mainly capture small aphids, which may prevent equal and appropriate coverage of the crop to be protected (Wratten, 1973). At low densities they are likely to die before they find suitable prey (Hodek, 1967). In the presented experiments low efficiency was demonstrated by low exploitation rates at low aphid densities.

(d) Young larvae have a very low daily food intake. The food intake starts growing exponentially from the end of the second larval stage (Fig. 1).

(2) Introduction of open cultures with $S$. avenae colonies into the greenhouse to maintain a permanent and secure food source for all stages of $A$. bipunctata, which may then spread into the greenhouse to keep levels of target pest species low.

(a) It was shown that $A$. bipunctata develops well when fed exclusively on $S$. avenae (i.e. before target pest species occur or once they have been successfully reduced to low levels). 
(b) It was shown that $A$. bipunctata has relatively good survival rates at low prey densities (Table 5) and that it has compensation mechanisms through exploitation efficiency (Fig. 2) and conversion efficiency (Table 4).

One problem with adult ladybirds is that they tend to go to the roof of the greenhouse, which would favour release of larvae or the introduction of a population with a range of instars. Other research suggests that combination with other aphidophagous predators such as lacewings and gall midges should be carefully considered to gain optimum results (Hindayana et al., 2001).

Future work should investigate the impact of mixed diets ( $S$. avenae and target pest aphid species in greenhouse), the influence of this diet during the larval stage on adult oviposition performance and the ability of $A$. bipunctata to control target pest species on a larger scale.

ACKNOWLEDGEMENTS. We thank G. Port and E. Okello from Newcastle University, UK, for help with the editing of the English manuscript.

\section{REFERENCES}

Agarwala B.K. 1991: Why do ladybirds (Coleoptera: Coccinellidae) cannibalize? J. Biosciences 162: 103-109.

Agarwala B.K. \& Dixon A.F.G. 1992: Laboratory study of cannibalism and interspecific predation in ladybirds. Ecol. Entomol. 17: 303-309.

BANKs C.J. 1957: The behaviour of individual coccinellid larvae on plants. Brit. J. Anim. Behav. 5: 12-24.

BIANCHI F.J.J.A. \& VAN DER WERF W. in press: Model evaluation of the function of prey in non-crop habitats for biological control by ladybeetles in agricultural landscapes. Ecol. Model.

Blackman R.L. 1967: The effects of different aphid foods on Adalia bipunctata and Coccinella 7-punctata L. Ann. Appl. Biol. 59: 207-219.

Bonhomme R. 2000: Bases and limits to using "degree-day" units. Eur. J. Agron. 13: 1-10.

Carter M.C., Dixon A.F.G. \& Sutherland D. 1984: Plant structure and the searching efficiency of coccinellid larvae. Oecologia 63: 394-397.

Dixon A.F.G. 1970: Factors limiting the effectiveness of the coccinellid beetle Adalia bipunctata (L.) as a predator of the sycamore aphid, Drepanosiphum platanoides (Schr.). J. Anim. Ecol. 39: 739-751.

FERRAN A. \& Dixon A.F.G. 1993: Foraging behaviour of ladybird larvae (Coleoptera: Coccinellidae). Eur. J. Entomol. 90: 383-402.

Frazer B.D. \& McGregor R.R. 1992: Temperature dependent survival and hatching rate of eggs of seven species of Coccinellidae. Can. Entomol. 124: 305-312.
Grevstad F.S. \& KlepetKa B.W. 1992: The influence of plant architecture on the foraging efficiencies of a suite of ladybird beetle on aphids. Oecologia 92: 399-404.

HämäläInen M., MarkKulla M. \& RaiJ T. 1975: Fecundity and larval voracity of four ladybeetle species (Col., Coccinellidae). Ann. Entomol. Fenn. 4: 124-127.

Hindayana D., Meyhofer R., Scholz D. \& Poehling H.-M. 2001: Intraguild predation among the hoverfly Episyrphus balteatus de Geer (Diptera: Syrphidae) and other aphidophagous predators. Biol. Control 20: 236-246.

Hodek I. 1967: Bionomics and ecology of predaceous Coccinellidae. Annu. Rev. Entomol. 12: 79-104.

HoDEK I. 1970: Coccinellids and the modern pest management. BioScience 20: 543-552.

KaluSHKov P.K. 1994: Longevity, fecundity and development of Adalia bipunctata. Anz. Schädlingsk. Pflsch. Umwsch. 67: 6-7.

KalushKov P.K. 1998: Ten aphid species as prey for Adalia bipunctata. Eur. J. Entomol. 95: 343-349.

KalushKov P.K. 1999: The effect of aphid prey quality on searching behaviour of Adalia bipunctata and its susceptibility to insecticides. Entomol. Exp. Appl. 92: 277-282.

MerRitT Hawkes O.A. 1920: Observations on the life history, biology and genetics of the ladybird beetle Adalia bipunctata (Mulsant). Proc. Zool. Soc. London 78: 475-490.

Ninkovic V., Al Abassi S. \& Pettersson J. 2001: The influence of aphid-induced plant volatiles on ladybird beetle searching behavior. Biol. Control 21: 191-195.

OlsZAK R.W. 1987: The occurrence of Adalia bipunctata (L.) (Coleoptera: Coccinellidae) in apple orchards and the effects of different factors on its development. Ekol. Polska 35: $755-765$.

Wilcoxon F. \& Wilcox R.A. 1964: Some Rapid Approximate Statistical Procedures. Lederle Laboratory Division of American Cyanamid Co., Pearl River, New York, 60 pp.

Wratten S.D. 1973: The effectiveness of the coccinellid beetle, Adalia bipunctata (L.) as a predator of the lime aphid, Eucallipterus tiliae L. J. Anim. Ecol. 42: 784-802.

Xia J.Y., VAn DeR Werf W. \& Rabbinge R. 1999: Temperature and prey density on bionomics of Coccinella septempunctata (Coleoptera: Coccinellidae) feeding on Aphis gossypii (Homoptera: Aphididae) on cotton. Environ. Entomol. 28: 307-314.

Yasuda H. \& Ohnuma N. 1999: Effect of cannibalism and predation on the larval performance of two ladybird beetles. Entomol. Exp. Appl. 93: 63-67.

ZAR J. 1999: Biostatistical Analysis. Prentice Hall International Inc, New Jersey, 931 pp.

Received December 8, 2003; revised April 19, 2004; accepted April 20, 2004 